Article

\title{
Improving Rural Accessibility: A Multilayer Approach
}

\author{
Elisabetta Vitale Brovarone *(1) and Giancarlo Cotella 1 \\ Interuniversity Department of Regional and Urban Studies and Planning (DIST), Politecnico di Torino, \\ 10125 Torino, Italy; giancarlo.cotella@polito.it \\ * Correspondence: elisabetta.vitale@polito.it
}

Received: 27 February 2020; Accepted: 2 April 2020; Published: 4 April 2020

\begin{abstract}
Rural territories are worse equipped than urban ones in terms of accessibility to services and opportunities, due to their scattered development and peripheral character. Increasing cuts to loss-making services in traditional public transport contributed to increased social inequality and marginality, in so doing undermining the livability of rural communities. In this light, improving accessibility is an essential prerequisite for the sustainable development of rural areas. Whereas demand responsive transport solutions are often seen as a panacea in circumstances where traditional services are not viable, their implementation is more challenging than it may seem, due to the potential barriers intrinsically related to the differential socioeconomic, cultural, and institutional features of places. Furthermore, enhancing transport offer is only one side of the multifaceted prism of rural accessibility, and the institution of effective multi-level and multi-sector governance mechanisms is a precondition to approach the mentioned challenges under a more comprehensive perspective. Drawing on the results of the European Territorial Observatory Network (ESPON) Urban-Rural Connectivity in Non-Metropolitan Areas (URRUC) project, the paper sheds light on this issue, exploring the accessibility challenges of rural areas and proposing a multilayer policy approach aimed at supporting decision-makers in improving rural accessibility across Europe.
\end{abstract}

Keywords: rural areas; accessibility; multilayer policies; governance; mobility

\section{Introduction}

Accessibility is a fundamental prerequisite for sustainable development, as an intrinsic right and condition of living. As a consequence of the intense processes of depopulation, ageing, and de-anthropization they have undergone since the second half of the last century, however, rural territories often suffer from scarce and inadequate access to basic services, amenities, and opportunities, resulting in territorial and socioeconomic marginalization [1-5]. Low density, scattered development, and the peculiar geomorphological characteristics of these areas are generally associated with considerable distances from basic services and from work and leisure opportunities. Those marginalization processes are at the same time the causes and consequences of scarce accessibility, which in rural territories is particularly challenging [6] and undermines the livability of rural communities. Moreover, due to their spatial and socio-economic conditions, rural territories are highly car-dependent $[7,8]$; traditional public transport services can hardly be efficient under such conditions, and those who are most affected are people who have limited access to car use [7-13]. Therefore, providing and supporting alternative forms of transport in rural areas is primarily aimed at counteracting transport exclusion. In turn, this has an influence on demographic trends, providing an adequate mobility offer not only to the elderly, but also to young people. To a lesser extent, alternatives to cars in rural areas can be also aimed at reducing emissions. However, as will be discussed further in this paper, transport-related emissions are not a primary concern for mobility and accessibility in low-density rural areas. 
A good number of empirical studies have shown that Demand Responsive Transport (DRT) constitutes a viable alternative to traditional public transport in rural areas [14-17]. Nevertheless, whereas DRT solutions are often hailed as the panacea for rural accessibility challenges, they are not exempt from limitations [9,18-21]. Complementary measures addressing rural accessibility from other perspectives and reducing the need to travel may also prove effective. Bringing service closer to dwellers, both materially and immaterially, upgrading local competences, and supporting local development are only some examples of the various possible actions that can contribute to make rural territories more accessible. Improving rural accessibility, therefore, implies acting on several aspects, and enhancing transport provision is only one element of this multifaceted prism. Moreover, local stakeholders often face difficulties in having a voice in the planning and operation of transport services, which are usually issues tackled at a higher scale, as well as, more in general, in playing active roles in territorial development strategies [22,23]. Bearing these challenges in mind, in order to develop successful interventions, the development of integrated policy packages is necessary, to be then managed through complex multi-level and multi-sector governance mechanisms $[24,25]$.

Drawing on the results of the European Territorial Observatory Network (ESPON) Urban-Rural Connectivity in Non-Metropolitan Areas (URRUC) project, this paper aims at shedding light on how to approach the introduced challenges, in so doing supporting policy-makers in unfolding the complexity that surrounds the promotion of rural accessibility. The main objective of the project was to contribute to improving connectivity and accessibility related to urban-rural linkages in four non-metropolitan areas, respectively located in the United Kingdom, Spain, Italy, and Sweden. Building on its outcomes, the authors propose a multilayer approach to rural accessibility, aimed at supporting policymakers in framing the accessibility issues that characterize their territories, in turn favoring the development of policy solutions that go beyond the delivery of transport services, by taking into consideration wider conditions and implications. After this introduction, Section 2 briefly frames the challenge of accessibility in relation to rural areas. The URRUC project is then presented in Section 3, describing its aims, case studies, and methodology. Drawing on the results of the project, Section 4 describes the multilayer approach to rural accessibility developed by the authors, whilst Section 5 discusses the empirical insights deriving from its application to the URRUC case studies. A final section rounds off the contribution, presenting its main concluding remarks, reflecting upon the opportunities and limits of the proposed approach, and paving the way for further research on the matter.

\section{Accessibility Challenges in Rural Areas}

The notion of accessibility, first introduced by Hansen at the end of the 1950s [26], has been the subject of a rich scientific debate in the field of territorial and urban studies. Accessibility well expresses the multiple interactions between the spatial characteristics of territories, their socio-economic structure, and the mobility of their inhabitants [27-29]. Since the second half of the last century, these complex interactions have been dealt with by numerous studies, and accessibility has been interpreted, defined, and calculated in multiple ways [30,31]. This article adopts the definition of Geurs and van Wee, according to which accessibility is "the extent to which land-use and transport systems enable (groups of) individuals to reach activities or destinations by means of a (combination of) transport mode(s)" [30] (p. 128). Moreover, as highlighted by the ESPON SeGI (Indicators and perspectives for services of general interests in territorial cohesion and development) research project in relation to services of general interest, mobility issues are often paralleled, hence worsened, by issues related to the availability and affordability of services [32-35].

In rural areas, and even more so in remote and mountain ones, the challenge of guaranteeing adequate levels of accessibility is particularly problematic, not only because of the geomorphological and settlement features, but also because of the socio-economic and cultural processes that have led to their progressive marginalization compared to centers offering services and development opportunities [22]. Already in 1979, in his book titled "Accessibility, the rural challenge" [6], Malcolm Moseley brought this topic to the forefront, pointing out the peculiarities and challenges that characterize rural territories 
and underlining how in these territories, even more than in the urban ones, different themes intertwine with accessibility, starting from the spatial and social distribution of values, capacities, and resources. As Moseley's seminal contribution suggests, to deal with the accessibility of territories that are significantly far from services and opportunities aggregated in urban centers, a change of perspective is required. Whereas urban areas' challenges were targeted through time by an increasing number of policies developed at the national and supranational levels in order to foster economic, social, and territorial cohesion [36], since the second half of the last century, most rural areas have undergone intense processes of depopulation, ageing, and de-anthropization $[1,2,4,5]$. The attraction exerted by urban poles, in particular towards the active population groups, has progressively emptied these areas, where, as a consequence, the ageing index has increased. The urban society has somehow expanded into the rural society, and in particular in the mountain one: on the one hand, physically, with a proliferation of second homes and accommodation facilities, on the other hand importing its own economic, political, and cultural models, and inducing the rarefaction of civitas, that is "that set of social ties, functions, services and institutions capable of offering citizens the advantages of a civilized life" [37], ([38] p. 15). As a result, services and amenities have progressively decreased since the second half of the last century, as the number of potential users needed to ensure their provision went away. The closure of many service locations and activities is therefore both a cause and a consequence of the dependence of rural dwellers on urban nodes (for an overview of the challenges related to the provision of services in rural areas, see [35]).

The low density and scattered housing fabric of small towns and villages, typical of these territories, make it difficult to operate traditional public transport services, which can hardly be efficient with such a low and dispersed demand [9-11,39,40]. Therefore, these territories are highly car-dependent, and the groups of users that are most affected by the lack of accessibility are those who, due to age, economic, or cultural barriers, do not have access to cars $[7,8,12,13]$. The population groups that are already vulnerable in themselves are therefore those most affected by the lack of accessibility, and this applies both within rural areas and in the connection with the nearest urban centers where basic services are located [41-43]. Moreover, as recently highlighted in the ESPON SUPER (Sustainable urbanization and land-use practices in European regions) research project, rural areas feature different patterns of settlement, some population living in villages, others in isolated farmhouses, some dispersed in polycentric networks, others aligned in linear corridors, some territories posing restrictions to sprawling, other being less restrictive [44]. Hence, the territorial density of rural areas provides just general information on the varied pattern of development, which has deep implications on the provision and operation of alternatives to single-use automobility.

Distance is undoubtedly a central issue in determining the conditions of the accessibility of these territories. The accessibility literature provides various methodological approaches to measuring spatial accessibility, from traditional "container-based" and "distance-based" approaches, to more complex two-step floating catchment area methods [45-49]. Catchment areas and threshold times are varied and floating depending on several factors, among which are the type of service or amenity, the mode, and the users' capabilities and habits. However, regardless of the various thresholds that can be set to measure accessibility (i.e., tolerable distance in minutes or spatial distance), rural areas very often suffer from lower spatial accessibility levels than urban ones. Moreover, in rural even more than in urban contexts, accessibility should be understood not only in its physical dimension, but also in terms of technological and cultural divide [16,50,51]. As already pointed out by Moseley, transport is only one of the components of accessibility, and in rural territories, physical distance challenges are accompanied by that of virtual distance: these territories generally have limited broadband infrastructure, which is essential to ensure innovative solutions in the provision of services (e.g., telemedicine and e-learning) that may make up for the lack of supply on-site. In addition, digital literacy is often lower in rural areas than in urban ones, which makes it even more difficult to activate such solutions [52]. Therefore, improving the accessibility of these territories means, even more than in urban centers, acting on several fronts, not only by enhancing mobility, infrastructural connections, and transport services, 
but also by acting on the local territorial capital, bringing (or bringing back) services, knowledge, and forms of interaction and know-how where they are missing or have been lost $[3,53]$.

While highlighting the limits of mono-directional, sectoral solutions and the need to develop more complex approaches that can count on integrated policy packages, the issues introduced above also pose a number of governance-related challenges to policy-makers aiming at improving the accessibility of rural areas. These challenges are in particular related to the territorial levels where decisions are made, in relation to problems that, due to their nature, often transcend local realities. In this light, the development of successful solutions to enhance the accessibility of rural areas seems to be strongly intertwined with the adoption of a multi-level and multi-sector governance perspective that allows the involved actors to unfold and manage the complexity that surrounds this issue [54]. This is the approach that has been adopted by the ESPON URRUC project, whose main features and outcomes will be further described in the sections that follow.

\section{Materials and Method: The ESPON URRUC Project}

The research methodology behind this contribution was developed within the research project URRUC (Urban-Rural Connectivity in Non-Metropolitan Areas; for additional information: https: //www.espon.eu/URRUC), a Targeted Analysis funded in the framework of the European Territorial Observatory Network (ESPON) in the period 2018-2019. The main objective of the project was to contribute to improving connectivity and accessibility related to urban-rural linkages in four non-metropolitan areas: (i) Scarborough Borough, (United Kingdom); (ii) Marina Alta (Spain); (iii) Valle Arroscia and the Province of Imperia (Italy); and (iv) Region Västerbotten (Sweden). Building on a continuous dialogue with a broad number of stakeholders active in the four territories at stake, the project aimed at improving the understanding of urban-rural mobility and accessibility challenges that characterize each case and, on this basis, developing appropriate policy solutions for improving rural accessibility therein. Furthermore, the project also focused on reflecting upon the actual potentials for the transferability of the identified solutions, in order to provide relevant knowledge applicable to other territories across Europe presenting similar accessibility challenges.

\subsection{The Four Empirical Case Studies}

The four case studies of the URRUC project share similar characteristics. They are coastal areas with poor connectivity and access to inner, rural areas. The size and dispersion of their populous make infrastructural development difficult. Major urban centers are located by the coast and suffer from congestion due to commuting flows at peak hours, also coming from inner areas. This is driven by the needs of rural households to access core services, employment opportunities, and education and recreational locations, which are primarily found in the largest urban areas. Investment in transport infrastructures and services is inadequate to meet these demands, as the nature of these territories, with small, dispersed populations, makes transport provision economically difficult and hardly justifies the expenditure. Optimizing transport solutions is further aggravated by seasonal flows associated with tourism.

More specifically, most of the rural and mountain areas of Marina Alta lack adequate access to services and opportunities, especially as far as those who do not have access to a car are concerned. Although the potential market for public transport is wide, public transport is almost not taken into account when planning a trip. Those who have access to a car use almost only this means of transport, both because of a lack of adequate alternatives and of a poor sustainable mobility culture. Weak horizontal and vertical coordination, fragmentation of competences, and different knowledge and priorities challenge the improvement of accessibility of rural areas, and flexible solutions face a rigid legislative frame and some resistance to change.

Rural areas and suburbs of Scarborough Borough Council lack alternatives to private cars for connections and accessibility to services of general interest. Social objectives prevail in such areas, whereas also economic ones are relevant for Scarborough; so connectivity is crucial, and road expansion 
is seen as a priority by the local stakeholders. Commuters mainly use a car (or a bike where possible) and are satisfied with their mobility; public transport is unreliable and used mainly for leisure, so those who do not have access to a car are very disadvantaged. Additional challenges concern the fragmentation of competences, and in particular the limited influence of the local level on the upper tiers.

The towns and hamlets of Valle Arroscia are dispersed over a wide mountainous territory, some of them being far from the main road axis of the valley. Most trips are made by car, and the current public transport system fails to meet the need of the few who rely on it. Hence, while car users are not in search of alternatives, some user groups suffer from territorial assignment. Public transport is seen as a last resort and at the same time poses serious challenges to those who rely on it to get to main urban nodes. Fragmentation of competences, different priorities, and a lack of vertical coordination between stakeholders involved in transport planning and operation raise challenges. Furthermore, local stakeholders have little influence on upper-tier decisions.

Västerbotten territory features rural settlements, most of them being accessible and some very remote. Territorial density is very low, and long distances and unfavorable weather strongly affect some user groups (i.e., those who do not have access to a car or inhabitants of remote hamlets in winter). To date, public transport is almost not considered as an option, and there is a lack of information on the existing services. Still, public transport is generally seen to have some interest, as well as digitalization of services. Vertical and horizontal cooperation is hampered by a lack of time and resources, and there seems to be no intention to increase investment in public transport, nor to finance potential solutions to improve connectivity in a cost-efficient way.

\subsection{Research Methodology}

One of the main tasks of the URRUC project was to develop "policy recommendations to further strengthening transport policy and systems related to urban-rural connectivity and interaction in non-metropolitan regions" [23] (p. 33). Firstly, building on the qualitative-quantitative case studies' analysis (statistical data, policy analysis, and interviews with regional and local stakeholders) and on a thorough review of the scientific literature and recent research projects, the research team developed four sets of policy recommendations, fitting the operational conditions and meeting the specific and general challenges of the stakeholders' territories. The recommendations were then reflected upon in relation to their potential to fit other non-metropolitan territories in Europe. This second step proved particularly complex, as a consequence of the challenges and barriers highlighted in the literature on policy transferability [55-58].

In order to provide support to policy-makers to enhance rural accessibility across Europe, a multi-layer approach was developed by the project team, composed of a number of complementary inductive and deductive steps (Figure 1). As will be presented more in detail, the information deriving from the most recent academic literature on the matter was complemented by the input collected iteratively from the case studies' stakeholders engaged in the project. In this way, the four case studies of the URRUC project were, at first, fundamental source of information in defining the methodology and then its main application testbeds. The proposed multilayer approach aimed at understanding accessibility issues and providing solutions going beyond the means of the delivery of transport services, by proposing also solutions not necessarily related to transport provision, as well as taking into consideration the conditions and implications of the wider context. On the one hand, this approach draws on marketing theory, which analyzes the possible penetration of a certain product on the market vis-à-vis the possible micro, meso, and macro level conditions and challenges $[10,59,60]$ and was similarly applied by Davison et al. to analyze the various challenges characterizing the implementation of DRT solutions at the operational level, at the task management level, and in the broader context $[10,21]$. On the other hand, it is deeply rooted in the interaction with the project stakeholders, which contributed to enhancing its soundness and coherence. 


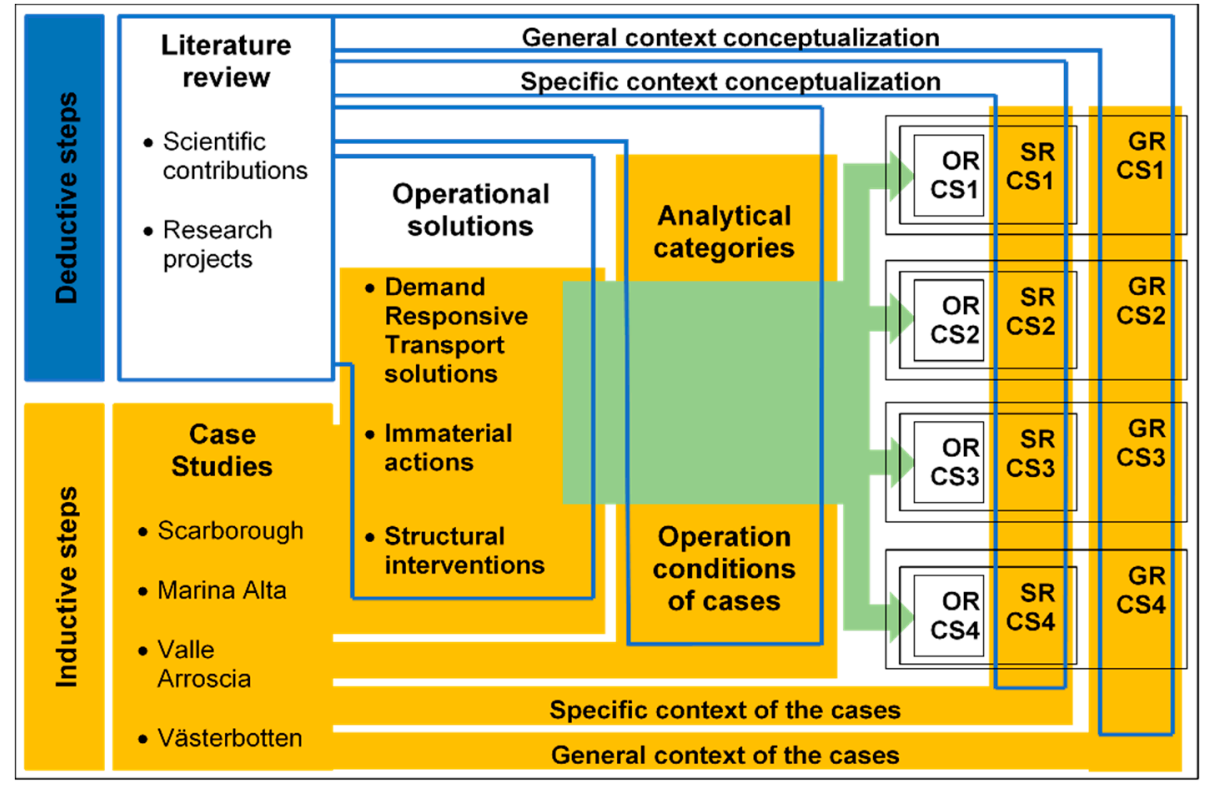

Figure 1. Methodological framework of the Urban-Rural Connectivity in Non-Metropolitan Areas (URRUC) multilayer approach. [61]. OR-operational recommendations; SR-specific recommendations; GR—general recommendations; CS—case study.

More specifically, a thorough review of both the academic literature and the recent international research projects related to (rural) accessibility led to the identification of a number of possible solutions aiming at improving accessibility and urban-rural connectivity in non-metropolitan regions. As far as flexible transport provision is concerned, ten possible alternatives to personal private automobility were streamlined: bus on demand, car clubs, car sharing, feeder, ride-sharing, shuttle van, social transport, taxis, shared taxicabs, village minibus. Furthermore, service delivery was considered among these alternatives, as a means to improve accessibility by limiting the need to travel. In this respect, logistics studies could provide useful information and methods in support of the evaluation of most suitable business models, the spatial distribution of consolidation centers, and the accessibility-maximizing location of government services [62-65]. Moreover, also a number of non-material and cross-cutting actions were taken into consideration among the alternatives to single-use automobility. These possible alternatives were assessed against a set of analytical categories identified in the literature $[10,16,17,21,66-70]$ and complemented by the case studies (Table S1):

- Geographical coverage: What type of area is the service covering? Categories: rural accessible, rural remote, hill/mountain accessible, internal mountain, suburb;

- Eligible users: Who are the main users? Categories: territorial assigned person, commuter, student, tourist;

- Type of use: Which kind of use is the service meant for? Categories: single user/small group, collective users;

- Booking: How do the users book their journey? Categories: phone (call/SMS), Internet (app/website), other (i.e., infopoints, on vehicle, etc.);

- Booking: When is booking required? Categories: on day/real-time, in advance ( $>$ one day), repeating (on regular basis);

- Timetable: How flexible is the timetable? Categories: on demand, fixed, mixed (i.e., on demand at fixed times);

- Route flexibility: How flexible is the route? Categories: fixed route, fixed route with possible deviations (i.e., within a corridor), fully flexible; 
- Routing pattern: Where are users picked-up/dropped-off? Categories: one-to-one, one-to-many/many-to-one, many-to-many;

- Vehicle size: What size of vehicle should be used? Categories: car, minibus/van, bus;

- Price: What is the price for the user? Categories: free/discounted, paid/standard, paid/premium;

- Financing: How is the service financed? Categories: subsidized, partly subsidized, commercial;

- Performance objectives: What kind of goal is the service meant to achieve? Categories: economic, social, environmental;

- Level of demand: What is the expected or measured level of demand (passengers per vehicle/hour [17])? Categories: very low/less than 10, low/between 10 and 20, medium/between 20 and 50, high/greater than 50.

The specific and general contexts that surround and influence the described operational aspects were then analyzed and assessed. The challenges for the promotion of better accessibility in the territories at stake were identified and analytically divided into two macro groups (specific and general), each further characterized by a number of sub-themes. Specific challenges encompassed elements that were specifically related to transport and mobility demand and provision, namely: market; customer perceptions; stakeholders. General challenges, on the other hand, comprised the general policy, economic, sociocultural, and technological contexts that surround transport and mobility.

The described multilayer approach allowed for the development of tailor-made policy recommendations for each of the project's case studies, in the form of comprehensive policy packages composed by operational, specific, and general inputs. Whereas the operational inputs mostly concerned the identification of the most fitting practical measures for the given territory, the specific and general recommendations were meant to reduce the barriers that currently hamper the implementation of measures to improve accessibility and urban-rural connectivity. In this phase as well, the combination of expert-led inputs (grounded on the elaboration of information from literature, data, and documents) with constant dialogue with regional and local stakeholders was very important to produce scientifically sound, place-sensitive outcomes. The section that follows presents in more detail this multilayer approach to rural accessibility, aimed at providing guidance to decision-makers in addressing and improving rural connectivity across Europe.

\section{Towards a Multilayer Policy Approach}

Building on the presented methodology and on the results generated by its implementation in the four target areas, the URRUC project team further refined the mentioned multilayer approach, so that it could support policy-makers in (i) analyzing the main conditions, challenges, and opportunities that characterize a territory and, on the basis of this analysis, (ii) defining and prioritizing integrated policy packages to enhance rural accessibility successfully. The various analytical categories composing this approach (Figure 2) are presented in the subsections below-respectively dealing with the operational, specific, and general layers- to be then composed into a multilayer matrix that, building on the actual priority and complexity of the proposed actions that were defined for each layer, allows weighting and assessing their deliverability potential. As will be further reflected upon in the Conclusions, the aim of the proposed approach was not to provide a ready-to-use decision on the basis of given conditions; rather, it constituted a structured methodology of analysis that should inform the different phases of the decision- and policy-making process, contributing to enhancing vertical (i.e., between actors at the different territorial levels) and horizontal (i.e., between different policy sectors) coordination. 


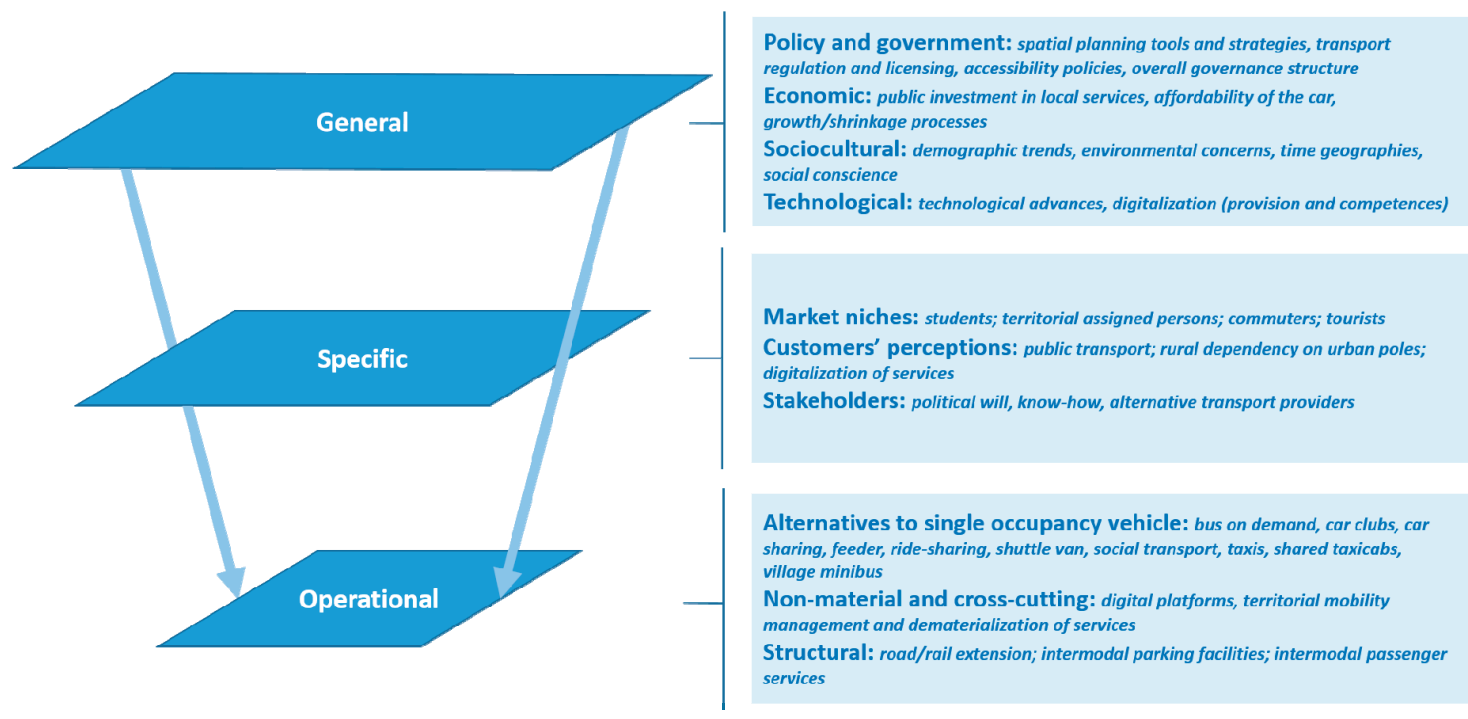

Figure 2. Multilayer approach and analytical categories for the operational, specific, and general layers.

\subsection{Operational Layer}

The operational layer refers to the provision of alternatives to personal private automobility, to the improvement of transport infrastructure, and to non-material and cross-cutting actions directly aimed at improving conditions for mobility. Whereas demand responsive transport and community transport are more suitable than traditional public transport services [14-17], at the same time, measures to promote localization and reduce the need to travel can be very relevant to enhance rural accessibility [71,72]. Moreover, these measures can counteract the magnetic effect that fast access to urban nodes exerts on rural areas, further worsening de-anthropization processes and socio-economic marginalization. In this respect, digitalization is a key element, as a prerequisite for smart and e-services, that can prove very effective in addressing rural accessibility challenges [73-79].

The relevance of each of the analytical categories mentioned in Section 3.2 can be assessed in relation to each territory to typify territorial features with respect to operational measures for accessibility (see Table S1, in the Supplementary Materials). In so doing, conditions are set for a pre-assessment of the actual goodness of fit to each of the mentioned alternatives to personal private automobility in relation to the specific operational conditions of each territory. Similarly, non-material and cross-cutting actions-i.e., digital platforms, territorial mobility management, and dematerialization of services-should be assessed, in particular in relation to the territorial level at which they would best be implemented, as well as to possible criticalities and barriers in terms of resources, digital coverage, and know-how of providers and users.

More in detail, digital platforms can help users in each phase of their trip [76] and may take different forms as for instance: trip planners helping users to choose the best solution for their trip (i.e., providing information on the route, cost, journey time, public transport lines, timetables, etc.); ticketing platforms helping users to get their tickets for single or multiple transport services or modes; ride-sharing platforms bringing together supply and demand and easing their interaction. Mobility management is "a concept for promoting sustainable transport and dealing with the question of car use by modifying the habits and behavior of travelers. The core of this mobility management is formed by 'soft' policy measures such as information and communication, organization of services and the coordination of activities of the various partners" [80] (p. 7). Territorial mobility management applies these principles at the supralocal level [81,82], aiming at improving mobility in the territory within its competence through the collaboration and coordination of local institutions (municipalities, schools, health services), local transport companies, associations of companies, and other categories. The dematerialization of services (as for instance telemedicine, telecare, e-learning, and e-government), despite its limitations in terms of the digital divide and the risk of further marginalization of territorial assigned persons, can potentially 
provide several economic, environmental, and social benefits $[73,75,78,83-85]$, all in all reducing the need to travel, making services virtually accessible everywhere. Finally, the operational layer may also comprise a number of interventions to improve mobility structurally and support multimodality, such as infrastructural interventions (road or rail extension), intermodal parking facilities for bikes and cars, and intermodal passenger transport (introduction of bike racks on buses or storage facilities on trains).

\subsection{Specific Layer}

As highlighted above, each the enhancements of accessibility in a given territory may also present a set of specific challenges. They concern the conditions, opportunities, and challenges that surround the operational layer and are specifically related to mobility and accessibility. Considering their implications for the actual provision of those operational solutions identified as fitting may pave the ground for the definition of integrated actions on the matter. Three main dimensions characterize this layer: market, customer perceptions, and stakeholders.

The first one concerns the market niches relying on or interested in alternatives to the private car. Understanding the users and their needs is very important in order to avoid spending resources on inadequate services and to understand key priorities, also regarding latent demand. Four types of users are deemed relevant to the analysis of market niches: (i) students; (ii) territorial assigned persons (i.e., unable to utilize traditional transport solutions due to physical, economic, or social constraints); (iii) commuters; and (iv) tourists. Each category features different needs in terms of space-time geographies [86-88], the volume of users, and flexibility (for instance, while students and commuters generally have systematic schedules and origins-destinations, other users, such as territorial assigned persons, have more variable requirements). Different market niches do not necessarily imply the need to provide different alternatives to single-use automobiles, but the analysis of market niches is a crucial brick of the specific layer, in order to bring into operation adequate services.

Customers' perceptions concern the attitude of people who are supposed to use the service $[89,90]$. More specifically, in rural and remote contexts, three main clusters should be taken into account: public transport; rural dependency on urban poles; digitalization of services. The attitude toward public transport is an issue, especially if it is seen as a last resort due to its low performance and attractiveness compared to automobility. How much rural dwellers "feel" dependent on urban nodes is another aspect that deserves attention: Is it always necessary to improve urban-rural connections or, in some cases, can enhancing the interconnection between polycentric rural networks be more viable? Moreover, attitudes towards the digitalization of services must be explored: besides the "hard" component of the digital divide, rural communities may lack digital competences or show some resistance to change.

Finally, a relevant role is played by stakeholders, in terms of political will, the know-how of actors that are assumed to be involved in policies and actions, and the presence of alternative transport providers. As the saying goes, where there is a will, there is a way; hence, political will is undoubtedly an aspect that must be taken into consideration, but for every government level that is involved in accessibility and transport provision. Rural areas frequently suffer from a mismatch between their priorities and those of upper levels of government, with the latter usually provided with higher decisional power on transport provision, but lower interest in rural accessibility challenges. As a consequence, local accessibility concerns may only be addressed by supralocal policies if efforts are made to set up multilevel governance processes aiming at vertical coordination (see Section 4.3) [91]. The know-how of actors that are assumed to lead the enhancement of rural accessibility is another important element that should be taken into consideration. Small rural administrations often rely on external consultants due to scarce internal institutional capacity, and this raises problems in relation to both public expenditures and local empowerment. Training and up-skilling key local staff in order to reduce dependence on external consultants would then, on the one hand, allow saving resources (that small rural municipalities are often lacking) and, on the other hand, set the conditions for long-term improvement of local know-how. Finally, the presence of alternative transport providers should be explored. Typically consisting of small local associations offering services to disadvantaged persons, 
these initiatives may also provide innovative services for tourists and the local population, in so doing enhancing rural accessibility. Hence, their availability to expand the services should be explored, in order to also gain insights into their operating model, the criticalities they are facing, etc.

\subsection{General Layer}

A final layer concerns aspects that are of a more general nature, but no less important and strategic than those presented above. These aspects may constitute challenges or advantages that can be crucial for the implementation of operational solutions and, more in general, for the enhancement of rural accessibility. Four main clusters should be considered: policy and government, economic, sociocultural, technological.

The policy and government context comprises a wide range of elements that have profound influences on the possibility of setting up and implementing policies and actions to improve accessibility. They concern existing spatial planning tools and strategies, transport regulation and licensing, accessibility policies, and more in general, the overall governance structure. Spatial planning tools, for instance, can set the conditions for either a disperse or dense urbanization, in so doing influencing the spatial distributions of generators and attractors of mobility flows [92]. Similarly, accessibility policies implemented at the local or regional level constitute the framework in which actions and interventions should fit. Moreover, flexible transport solutions suitable for addressing rural accessibility often collide with the existing legislative frameworks, or with rigid mindsets according to which the latter are applied. Finally, whereas a multilevel governance system would ease the coordination of actors from different territorial levels, in rural settings, small local administrations often face difficulties in dialoguing and advocating their needs vis-à-vis upper administrative levels.

The economic context influences the feasibility and the relevance of the possible actions aiming at improving rural accessibility. Three main aspects are deemed as particularly relevant: public investment in local services, cars' affordability, and growth/shrinkage processes. As mentioned in Section 2, public investment in local services is often decreasing in rural areas. Analyzing public investment in local services can help to identify, on the one hand, reasonable measures to improve accessibility and, on the other hand, margins for improvement and actors to urge. Cars' affordability is another relevant element: whereas a context in which the car is less affordable could be more prone to the use of public transport than a wealthy one, on the other hand, accessibility and social equity issues can be very challenging, especially in contexts in which public expenditure on local transport is cut to the bone. Finally, the mixed impacts of growing or shrinking dynamics should be also taken into account: whereas shrinking processes and economic downturn, for instance, are expected to worsen public transport provision, the economic pressure they exert may also contribute to increasing public transport patronage and overcoming resistance to change and cooperation among sectors and levels of governance [23,93].

The sociocultural context concerns demographic trends, environmental concerns, time geographies, and social conscience. The evaluation of demographic trends, to a large extent related to the growth/shrinking dynamics mentioned above, allows framing accessibility issues and transport provision with respect to a general estimate of the expected volumes and age composition of demand [94]. The analysis of the demographic distribution is of key importance to pre-assess the demand for alternative forms of transport and to identify social groups for which they may be particularly important. Moreover, it can also support the definition of actions aimed at satisfying latent demand and at reversing demographic trends. The environmental concerns of rural dwellers can provide further insights to evaluate which measures to put in place and how to communicate them. Especially in remote, sparsely populated areas that generally have high natural values and low anthropogenic pressures, environmental concerns with respect to the impacts of car use are not of particular relevance, except for touristic destinations with high volumes of flows. In these contexts, policies to rebalance modal split in favor of public transport and to promote alternatives to the single-user private car would face resistance if they wanted to leverage environmental aspects. Other elements, such as social or 
economic aspects, should be prioritized for justifying and communicating such policies. Moreover, the current and expected time geographies of target users can provide very important information for designing solutions [95], and the same is true for information concerning social conscience and cohesion. In particular, high social cohesion, a sense of belonging, and strong local social capital are indeed very important in conferring mobility, especially in rural, low-density areas [96].

Lastly, the technological context concerns those innovative and flexible solutions that can be put into practice given the adequate digitalization of rural territories. Technological advances, i.e., in programming and software, can offer new potential solutions for flexible transport systems and alternatives to the private car. Furthermore, the digitalization, in terms of broadband coverage and users' competences, is a necessary precondition for the implementation and effectiveness of such measures and for smart rural communities [79].

\subsection{Shaping Decisions: Priority, Complexity, Deliverability}

After having analyzed the conditions and challenges of a given territory and identified their implications in terms of potential recommendations, this multifaceted information should be systematized into a synthetic chart, allowing for its multilayer, integrated interpretation. This activity encompasses two main steps: firstly, as a sort of ID card of the area, a table summarizing its conditions and challenges at the operational, specific, and general level is produced. Subsequently, on the basis of the assessment of these conditions and challenges, potential measures and recommendations to improve accessibility are defined for each level, and their deliverability is assessed on the basis of a number of variables: priority, complexity, time-frame, provider, actions, and outcomes (Figure 3).

\section{Deliverability}

\begin{tabular}{|c|c|c|c|c|c|}
\hline \multirow{4}{*}{ 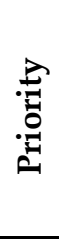 } & Low & Medium-low & Medium-low & Low & Low \\
\hline & Medium-low & Medium-high & Medium-high & Medium-low & Low \\
\hline & Medium-high & High & Medium-high & Medium-high & Medium-low \\
\hline & High & High & High & Medium-high & Medium-low \\
\hline & & Low & Medium-low & Medium-high & High \\
\hline & & \multicolumn{4}{|c|}{ Complexity } \\
\hline
\end{tabular}

Figure 3. Deliverability matrix.

Ideally, the compilation of these two tables should facilitate the interaction of decision and policymakers at various territorial levels and allow for the development of a structured overall assessment of their priorities and, in turn, more thorough programming of an integrated policy package to improve rural accessibility. The ID card is aimed at summarizing the various elements that were highlighted in the previous phases for each layer. This table should be brief and concise, taking no more than one page. In so doing, it offers an easily readable overview of operational conditions and specific and general challenges. This can support decision-makers in gaining integrated knowledge of the complex, multifaceted system of elements that have implications on rural accessibility. Based on the ID card and on the detailed information produced for each layer, a shortlist of recommendable measures and actions is defined, aiming at reducing the barriers that currently hamper the implementation of measures to improve accessibility and urban-rural connectivity. Each shortlisted action is then assessed in relation to its actual priority and complexity in the respective territory (in the scale low, medium-low, medium-high, high). Combining the priority and the complexity of each action, its deliverability is determined, again on a scale of four (Figure 4). As an example, an action ranked with low priority and high complexity will result in a low deliverability rate, while an action with high priority and low complexity will result in being highly deliverable. This assessment activity should be performed jointly with the various stakeholders engaged in the process, in order to combine and exploit synergies 
between expert knowledge and local stakeholders' knowledge of the territory. As far as the URRUC case studies are concerned, whose results are presented in the section that follows, this has occurred through the continuous interaction between the project research team and the stakeholders active in each of the four territorial contexts.

\begin{tabular}{|c|c|c|c|c|c|c|}
\hline Recommendation & $\begin{array}{c}\text { Priority }(1= \\
\text { Highest } \\
\text { Priority, } 4= \\
\text { Lowest } \\
\text { Priority) }\end{array}$ & $\begin{array}{l}\text { Complexity (1 } \\
\text { = Least } \\
\text { Complexity, } 4 \\
=\text { Most } \\
\text { Complexity) }\end{array}$ & $\begin{array}{l}\text { Time } \\
\text { Frame } \\
\text { (Short, } \\
\text { Medium, } \\
\text { Long- } \\
\text { term) } \\
\end{array}$ & $\begin{array}{c}\text { Provider } \\
\text { (Public, } \\
\text { Private or } \\
\text { Third } \\
\text { Sector) }\end{array}$ & $\begin{array}{l}\text { Actions } \\
\text { (Steps which } \\
\text { need to be } \\
\text { followed to } \\
\text { put solution } \\
\text { into place) }\end{array}$ & $\begin{array}{c}\text { Outcomes } \\
\text { (Who benefits } \\
\text { and impacts) }\end{array}$ \\
\hline \multicolumn{7}{|c|}{ OPERATIONAL RECOMMENDATIONS } \\
\hline \multicolumn{7}{|l|}{ Solution 1} \\
\hline \multicolumn{7}{|l|}{ Solution 2} \\
\hline \multicolumn{7}{|l|}{$\ldots$} \\
\hline \multicolumn{7}{|l|}{ Solution $\mathbf{n}$} \\
\hline \multicolumn{7}{|c|}{ SPECIFIC RECOMMENDATIONS } \\
\hline \multicolumn{7}{|l|}{ Solution 1} \\
\hline \multicolumn{7}{|l|}{ Solution 2} \\
\hline \multicolumn{7}{|l|}{$\ldots$} \\
\hline \multicolumn{7}{|l|}{ Solution $\mathbf{n}$} \\
\hline \multicolumn{7}{|c|}{ GENERAL RECOMMENDATIONS } \\
\hline \multicolumn{7}{|l|}{ Solution 1} \\
\hline \multicolumn{7}{|l|}{ Solution 2} \\
\hline \multicolumn{7}{|l|}{$\ldots$} \\
\hline \multicolumn{7}{|l|}{ Solution $n$} \\
\hline Deliverability & High & Medil & n-high & Mediun & & Low \\
\hline
\end{tabular}

Figure 4. Format of the deliverability plan. Source: [61].

\section{Empirical Insights and Discussion}

The introduced multilayer approach was tested in the ESPON URRUC case studies (i.e., Marina Alta, Scarborough, Valle Arroscia, and Vasterbotten), allowing collecting a number of empirical insights that are discussed here. Figure 5 synoptically represents the recommendations made for the case studies, highlighting their priority, complexity, and deliverability, deriving from the assessment that was performed for each case. Depicting the result of the inductive-deductive approach described in Section 3, this representation provides insight into the similarities and peculiarities of the four case studies. In so doing, it set the ground for discussion and for the definition of recommendations for other EU non-metropolitan regions facing rural accessibility challenges.

As regards the operational layer, recommended alternatives to a single-use car were picked for each territory among the 11 possible solutions that were previously streamlined (bus on demand, car clubs, car sharing, feeder, ride-sharing, service delivery, shuttle van, social transport, taxis and shared taxicabs, village minibus). Similarly, the non-material and digital solutions that were recommended refer to the three common clusters that were analyzed and assessed for all the case studies (digital platforms, mobility management, and dematerialization of services). The synoptic representation shows how in each of the case studies, the relevance and deliverability varied, depending on the respective territorial specificities. 


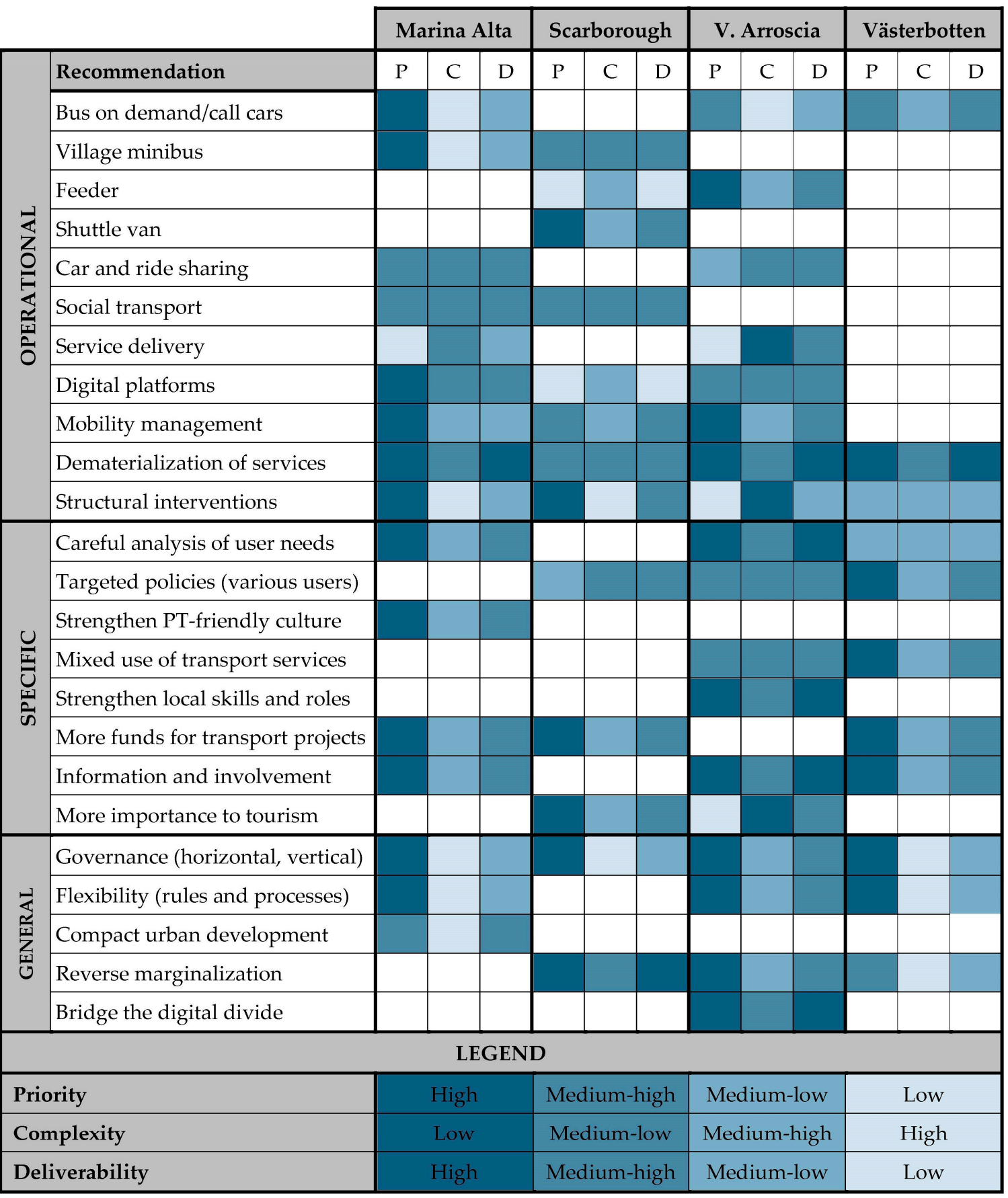

Figure 5. Synoptic analysis of case studies' recommendations, according to their priority, complexity, and deliverability in each case study.

A more varied picture emerges from the specific and general recommendations. Sixteen different specific recommendations and fourteen general recommendations were developed and then respectively clustered into eight and five coherent groups for the sake of clarity. More in detail, for the specific layer, the following recommendations were brought forward:

- Careful analysis of users' needs, in order to avoid spending resources on inadequate services and to understand key priorities, also regarding latent demand for alternatives to the single-use private car. 
- Targeted policies (various users), to draw up policies that directly respond to the needs of targeted groups.

- Strengthen a public transport-friendly culture, addressing the main issues that today make public transport unappealing and underused.

- Mixed use of transport services, widening the number of user groups allowed to use services (i.e., school bus open to other user groups than students) and possibly combining passenger and freight transport (where adequate).

- Strengthen local skills and roles, training and up-skilling key staff in order to reduce dependence on external consultants and to set the conditions for long-term improvement of local know-how and planning skills.

- More funds for transport projects, to dedicate more funding to local transport policies and projects, also through the integration of diverse funding.

- Information and involvement, to favor the diffusion of information among residents and tourists and foreign users, about the services, also through extensive communication, information, and training campaigns on innovation, grounded on participation, targeted to all user groups.

- More importance to tourism, to give more importance to the needs and effects of tourism on transport, adapting the system to the seasonality of flows and/or dedicating specific transport services for tourism (especially in touristic areas).

For the general layer, the following inputs were suggested:

- Governance (horizontal and vertical), to foster interaction among levels and sectors, possibly through permanent working groups, to prevent missing links, incoherence, and inefficiencies.

- Flexibility (rules and procedures), to work towards a more flexible legislative framework and towards more flexibility in applying legal rules and principles.

- Compact urban development, to pay more attention to the containment of land consumption and dispersed settlements, to reverse conditions that lead to such a dispersed demand.

- Reverse marginalization, to provide the preconditions to reverse the processes that led to marginalization.

- Bridge the digital divide, overcoming physical and social barriers linked to digitalization, both through digital provision and communication and information actions.

The recommendations shown in Figure 5 are the result of a selection and merging process; therefore, they represent the elements that the four case studies deemed as most relevant. Moreover, the synoptic representation allowed discussing the relevance of some recommendations, especially those that are recurring in three or more case studies, as well as some peculiar and some common issues about complexity and deliverability.

Focusing on those operational recommendations that recurred in three or more case studies, it emerged that the majority of cases opted for the bus on demand, that is turning current traditional bus lines into on-demand services (with the same route). Other options, such as car and ride-sharing and feeder buses, were of interest to fewer cases. Indeed, case-specific elements make one alternative more viable than others. Bus on demand is the most general and closer to current services of the proposed alternatives; hence, the preference for this solution may be also due to familiarity with the concept and slight resistance to change. Nevertheless, while bus on demand was highly recommended, the complexity of delivering it was rated from high to very high. This was due to elements that pertained to the specific and general layers-such as governance, flexibility of rules and procedures, and know-how-which will be discussed later in this section. Moreover, non-material actions were highly recommended by most of the case studies. While the priority of digital platform varied much among the case studies, mobility management and dematerialization of services were ranked as high or very high by all the case studies. Especially dematerialization of services was considered as high priority by all the case studies, and its complexity was deemed as not particularly relevant. 
The importance that was given to non-material actions highlighted and confirmed the relevance of complementary solutions to transport provision tout court to improve rural accessibility. Structural interventions were also recommended by all the case studies, but with wide-ranging priority and complexity. Indeed, structural improvements in transport infrastructures are often needed in rural contexts, but their relevance and complexity are highly context-dependent.

For the specific layer, the most relevant issues concerned the analysis of demand, the optimization of services for targeted users, the funding, and information for stakeholders and users. Priority and complexity varied among the case studies, depending on territorial specificities, and especially on the availability of data and surveys on local demand for public transport. The in-depth analysis of user needs and the definition of targeted policies for single or multiple target users were acknowledged as key elements for the provision of adequate and efficient services. Moreover, funding issues were highlighted as very relevant by most of the case studies. In this case, priority and complexity were ranked uniformly: while they were a very high priority, also their complexity was quite high, both because of a lack of resources and of dependence on upper-level government authorities having little concern about the local accessibility issues of rural areas. Information and involvement of users and stakeholders was another aspect that was highly recommended by most of the case studies, as an enabler of the feasibility and success of measures to improve accessibility.

For the general layer, governance and flexibility were acknowledged as key enablers of rural accessibility. The four case studies unanimously highlighted horizontal and vertical governance issues as a high priority, and most of them also remarked about the priority of making rules and procedures more flexible, to allow the introduction of alternative and innovative transport services. At the same time, the complexity of acting on those very relevant issues was assessed as high or very high. Indeed, local authorities have very limited influence and room for maneuver on those aspects and often suffer the consequences of upper-level, spatially-blind decisions. Finally, an overarching issue that was mentioned as very important and high-priority, but at the same time hard to deliver, was providing the preconditions to reverse the processes that led to marginalization.

\section{Concluding Remarks and Future Research Perspectives}

The proposed contribution presented the results of the project ESPON URRUC, aiming at developing recommendations towards better accessibility and connectivity in four non-metropolitan regions in Europe and, more in general, in all territories sharing similar characteristics to those under scrutiny in the project. Building on the results of the project, and acknowledging the growing relevance of this issue and, at the same time, the marginal role it still plays in the academic literature focusing on accessibility, the authors provided a contribution to the ongoing debate by proposing a multilayer approach that could support decision- and policy-makers in their activity.

Rather than resembling quantitative decision support systems and models, the proposed approach focused on the interaction between stakeholders and on the joint identification of operational conditions and specific and general challenges that frame, and often constrain, urban-rural connectivity issues. On this basis, it guided stakeholders in the process of "weighting" the various potential solutions vis-à-vis the identified conditions and challenges, in so doing allowing them to assess their priority and complexity, and eventually their deliverability. Importantly, its aim was neither to address one-size-fits-all ready-to-use solutions on the basis of given conditions, nor to advocate in favor of policy blueprint and emulation. On the contrary, it should constitute a structured methodology to help stakeholders approach challenges jointly, in a process of co-production of integrated, multi-faceted policy packages. In so doing, it should inform the different phases of the decision- and policy-making process, allowing the involved players to reflect on the multiple aspects of accessibility and connectivity and to define, assess, and prioritize the variety of actions that can be made to improve accessibility. Similarly, it raised awareness in relation to the importance to carefully consider the highly heterogeneous institutional conditions for territorial governance and spatial planning in Europe (for an overview, 
see [97]), in so doing providing a contribution in the direction of the successful transfer of policies from one context to another [55-57].

Overall, the application of the multilayer approach in the four URRUC territories helped the involved stakeholders to realize that, before designing operational solutions, it was necessary to act on the underlying preconditions for improving the accessibility of rural areas. Issues of governance, legislation, and sociocultural aspects were revealed to be strong barriers that would thwart any attempt to provide alternative services. Hence, before trying to implement those services, it was necessary to reflect on such preconditions. This acknowledgement allowed for the development of integrated policy packages, aiming at enhancing vertical (i.e., between actors at the different territorial levels) and horizontal (i.e., between different policy sectors) coordination towards greater rural accessibility.

Whereas the proposed approach was far from being exhaustive, its objective was to stimulate and support policy- and decision-makers in EU non-metropolitan regions to think in innovative terms about transport and connectivity challenges and potentials that characterize their territories. The approach and methodology presented in this paper were tested only in the four case-study areas. Dialogue with the stakeholders helped to identify possible improvements, and more research is needed, especially to consolidate the weight assignment system, to apply the approach in other territorial contexts, to further examine other components of rural accessibility, and to refine the methodology accordingly. Finally, an in-depth discussion of the varied and complex system of interactions between patterns of development, spatial planning, and mobility in rural areas is undoubtedly worth further investigation.

Supplementary Materials: The following are available online at http://www.mdpi.com/2071-1050/12/7/2876/s1: Table S1: Alternatives to single-occupancy vehicle assessment matrix.

Author Contributions: Conceptualization, G.C. and E.V.B.; methodology, G.C. and E.V.B.; formal analysis, E.V.B.; investigation, G.C. and E.V.B.; writing, original draft preparation, E.V.B.; writing, review and editing, G.C. and E.V.B.; validation, G.C and E.V.B.; visualization, G.C. and E.V.B.; supervision, G.C.; project administration, G.C.; funding acquisition, G.C. and E.V.B. All authors read and agreed to the published version of the manuscript.

Funding: This research was funded by the European Observation Network for Territorial Development and Cohesion, ESPON 2020.

Acknowledgments: The authors would like to express their gratitude to all the members of the ESPON URRUC Research Consortium, and in particular to the colleagues from the University of Coventry, Nordregio, and the University of Valencia. Moreover, they would like to thank the stakeholders involved in the project: Elice Bacci and Piero Pelassa (Liguria, Italy), Alex Richards and Jim Dillon (Scarborough, United Kingdom), Rosario Donderis and María Jesús García (Marina Alta, Spain), Bianca Byring and Heidi Thornberg (Västerbotten, Sweden), as well as Nicolas Rossignol from the ESPON EGTC, for their continuous proactive engagement with the project activities.

Conflicts of Interest: The authors declare no conflict of interest.

\section{References}

1. Johnson, K.M.; Lichter, D.T. Rural Depopulation: Growth and Decline Processes over the Past Century. Rural Sociol. 2019, 84, 3-27. [CrossRef]

2. Montalvo, J.; Ruiz-Labrador, E.; Montoya-Bernabéu, P.; Acosta-Gallo, B. Rural-Urban Gradients and Human Population Dynamics. Sustainability 2019, 11, 3107. [CrossRef]

3. Schwanen, T.; Lucas, K.; Akyelken, N.; Cisternas Solsona, D.; Carrasco, J.A.; Neutens, T. Rethinking the links between social exclusion and transport disadvantage through the lens of social capital. Transp. Res. Part A Policy Pract. 2015, 74, 123-135. [CrossRef]

4. Vasta, A.; Figueiredo, E.; Valente, S.; Vihinen, H.; Nieto-Romero, M. Place-Based Policies for Sustainability and Rural Development: The Case of a Portuguese Village "Spun" in Traditional Linen. Soc. Sci. 2019, 8, 289. [CrossRef]

5. Viñas, C.D. Depopulation Processes in European Rural Areas: A Case Study of Cantabria (Spain). Eur. Countrys. 2019, 11, 341-369. [CrossRef]

6. Moseley, M.J. Accessibility: The Rural Challenge; Methuen: London, UK, 1979.

7. Gray, D.; Farrington, J.; Shaw, J.; Martin, S.; Roberts, D. Car dependence in rural Scotland: Transport policy, devolution and the impact of the fuel duty escalator. J. Rural Stud. 2001, 17, 113-125. [CrossRef] 
8. Shergold, I.; Parkhurst, G.; Musselwhite, C. Rural car dependence: An emerging barrier to community activity for older people. Transp. Plan. Technol. 2012, 35, 69-85. [CrossRef]

9. Daniels, R.; Mulley, C. Flexible Transport Services: Overcoming Barriers to Implementation in Low-Density Urban Areas. Urban Policy Res. 2012, 30, 59-76. [CrossRef]

10. Davison, L.; Enoch, M.; Ryley, T.; Quddus, M.; Wang, C. Identifying potential market niches for Demand Responsive Transport. Res. Transp. Bus. Manag. 2012, 3, 50-61. [CrossRef]

11. Farrington, J.; Farrington, C. Rural accessibility, social inclusion and social justice: Towards conceptualisation. J. Transp. Geogr. 2005, 13, 1-12. [CrossRef]

12. Mattioli, G. Where Sustainable Transport and Social Exclusion Meet: Households Without Cars and Car Dependence in Great Britain. J. Environ. Policy Plan. 2014, 16, 379-400. [CrossRef]

13. Verma, I.; Taegen, J. Access to Services in Rural Areas from the Point of View of Older Population-A Case Study in Finland. Int. J. Environ. Res. Public Health 2019, 16, 4854. [CrossRef] [PubMed]

14. Alonso-González, M.J.; Liu, T.; Cats, O.; Van Oort, N.; Hoogendoorn, S. The Potential of Demand-Responsive Transport as a Complement to Public Transport: An Assessment Framework and an Empirical Evaluation. Transp. Res. Rec. 2018, 2672, 879-889. [CrossRef]

15. Mulley, C.; Nelson, J.D. Paratransit: Shaping the Flexible Transport. Future (Transport and Sustainability Volume 8); Emerald Group Publishing Limited: Bingley, UK, 2016.

16. Velaga, N.R.; Beecroft, M.; Nelson, J.D.; Corsar, D.; Edwards, P. Transport poverty meets the digital divide: Accessibility and connectivity in rural communities. J. Transp. Geogr. 2012, 21, 102-112. [CrossRef]

17. Wright, S. Designing flexible transport services: Guidelines for choosing the vehicle type. Transp. Plan. Technol. 2013, 36, 76-92. [CrossRef]

18. Afonso, P.; Telhada, J.; Carvalho, M.S. Incorporating Economic Issues in the Design of Sustainable DRT Systems: Insights from the Case of a Portuguese Municipality. In Proceedings of the 2016 IEEE 19th International Conference on Intelligent Transportation Systems (ITSC), Rio de Janeiro, Brasil, 1-4 November 2016.

19. Avermann, N.; Schlüter, J. Determinants of customer satisfaction with a true door-to-door DRT service in rural Germany. Res. Transp. Bus. Manag. 2020, 100420. [CrossRef]

20. Banister, D. Community Transport for Rural Areas: Panacea or Palliative? Built Environ. 1982, 8, $184-189$.

21. Davison, L.; Enoch, M.; Ryley, T.; Quddus, M.; Wang, C. A survey of Demand Responsive Transport in Great Britain. Transp. Policy 2014, 31, 47-54. [CrossRef]

22. Cotella, G.; Vitale Brovarone, E. The Italian National Strategy for Inner Areas: A Place-Based Approach to Regional Development. In Dilemmas of Regional and Local Development; Bański, J., Ed.; Routledge: Abingdon, UK, 2020; ISBN 978-1-138-35915-4.

23. ESPON. URRUC - Urban-Rural Connectivity in Non-Metropolitan Regions. Final report; European Territorial Observatory Network: Luxembourg, 2019.

24. Givoni, M.; Macmillen, J.; Banister, D.; Feitelson, E. From Policy Measures to Policy Packages. Transp. Rev. 2013, 33, 1-20. [CrossRef]

25. Stead, D. Dimensions of territorial governance. Plan. Theory Pract. 2013, 14, 142-147. [CrossRef]

26. Hansen, W.G. How Accessibility Shapes Land Use. J. Am. Inst. Plan. 1959, 25, 73-76. [CrossRef]

27. Bertolini, L. Planning the Mobile Metropolis: Transport for People, Places and the Planet; Macmillan Education: London, UK, 2017; ISBN 978-0-230-30876-3.

28. Geurs, K.T.; Dentinho, T.P.; Patuelli, R. Accessibility, Equity and Efficiency. Part 1: Introduction. In Accessibility, Equity and Efficiency. Challenges for Transport and Public Services; Geurs, K.T., Patuelli, R., Dentinho, T.P., Eds.; Edward Elgar: Cheltenam, UK, 2016; pp. 3-8.

29. Venter, C. Developing a Common Narrative on Urban Accessibility: A Transportation Perspective; The Brooking Institution: Washington, DC, USA, 2016.

30. Geurs, K.T.; van Wee, B. Accessibility evaluation of land-use and transport strategies: Review and research directions. J. Transp. Geogr. 2004, 12, 127-140. [CrossRef]

31. Silva, C.; Pinto, N.; Bertolini, L. Designing Accessibility Instruments: Lessons on Their Usability for Integrated Land Use and Transport Planning Practices; Routledge: London, UK, 2019; ISBN 1-315-46359-8.

32. ESPON. SeGI-Indicators and Perspectives for Services of General Interest in Territorial Cohesion and Development-Final Report; ESPON Coordination Unit: Luxembourg city, Luxembourg, 2013.

33. Komornicki, T. Europa XXI 23 (2013), Editorial. Europa XXI 2013, 23, 5. 
34. Milbert, A.; Breuer, I.M.; Rosik, P.; Stepniak, M.; Velasco, X. Accessibility of services or general interest in Europe. Rom. J. Reg. Sci. 2013, 7, 37-65.

35. Rauhut, D.; Komornicki, T. The Challenge of SGI Provision in Rural Areas. In Proceedings of the 55th Congress of the European Regional Science Association: "World Renaissance: Changing Roles for People and Places", Lisbon, Portugal, 25-28 August 2015.

36. Cotella, G. The Urban Dimension of EU Cohesion Policy. In Territorial Cohesion; Medeiros, E., Ed.; Springer: Cham, Switzerland, 2019; pp. 133-155.

37. Dematteis, G. Polycentric urban regions in the Alpine space. Urban Res. Pract. 2009, 2, 18-35. [CrossRef]

38. Dematteis, G. La città ha bisogno della montagna. La montagna ha diritto alla città. Sci. Territ. 2016, 4, 10-17.

39. Bacci, E.; Cotella, G.; Vitale Brovarone, E. La sfida dell'accessibilità nelle aree interne: Riflessioni a partire dalla Valle Arroscia. Territorio 2020, in press.

40. Li, X.; Quadrifoglio, L. Feeder transit services: Choosing between fixed and demand responsive policy. Transp. Res. Part C Emerg. Technol. 2010, 18, 770-780. [CrossRef]

41. Black, N.; Scott, K.; Shucksmith, M. Social inequalities in rural England: Impacts on young people post-2008. J. Rural Stud. 2019, 68, 264-275. [CrossRef]

42. Ferreira, L.; Charles, P.; Tether, C. Evaluating Flexible Transport Solutions. Transp. Plan. Technol. 2007, 30, 249-269. [CrossRef]

43. Shergold, I.; Parkhurst, G. Operationalising 'sustainable mobility': The case of transport policy for older citizens in rural areas. J. Transp. Geogr. 2010, 18, 336-339. [CrossRef]

44. ESPON. SUPER-Sustainable Urbanization and Land Use Practices in European Regions; ESPON EGTC: Luxembourg city, Luxembourg, 2020.

45. Luo, W.; Wang, F. Measures of Spatial Accessibility to Health Care in a GIS Environment: Synthesis and a Case Study in the Chicago Region. Environ. Plan. B Plan. Des. 2003, 30, 865-884. [CrossRef]

46. Kanuganti, S.; Sarkar, A.K.; Singh, A.P. Quantifying Accessibility to Health Care Using Two-step Floating Catchment Area Method (2SFCA): A Case Study in Rajasthan. Transp. Res. Procedia 2016, 17, 391-399. [CrossRef]

47. Kompil, M.; Jacobs-Crisioni, C.; Dijkstra, L.; Lavalle, C. Mapping accessibility to generic services in Europe: A market-potential based approach. Sustain. Cities Soc. 2019, 47, 101372. [CrossRef]

48. Mao, K.; Li, M.; Huang, Q.; Chen, C.; Hu, W.; Chen, D. Evaluation of Spatial Accessibility to Town and Rural in a GIS environment: A case Study of Dachang County. In Proceedings of the 2011 19th International Conference on Geoinformatics, Shanghai, China, 24-26 June 2011.

49. Page, N.; Langford, M.; Higgs, G. Measuring Spatial Accessibility to Services within Indices of Multiple Deprivation: Implications of Applying an Enhanced Two-Step Floating Catchment Area (E2SFCA) Approach. Appl. Spat. Anal. Policy 2019, 12, 321-348. [CrossRef]

50. Philip, L.; Cottrill, C.; Farrington, J.; Williams, F.; Ashmore, F. The digital divide: Patterns, policy and scenarios for connecting the 'final few' in rural communities across Great Britain. J. Rural Stud. 2017, 54, 386-398. [CrossRef]

51. Philip, L.; Williams, F. Remote rural home-based businesses and digital inequalities: Understanding needs and expectations in a digitally underserved community. J. Rural Stud. 2019, 68, 306-318. [CrossRef]

52. Malecki, E.J. Digital development in rural areas: Potentials and pitfalls. J. Rural Stud. 2003, 19, $201-214$. [CrossRef]

53. Geels, F.W.; Sovacool, B.K.; Schwanen, T.; Sorrell, S. Sociotechnical transitions for deep decarbonization. Science 2017, 357, 1242-1244. [CrossRef]

54. Solly, A.; Berisha, E.; Cotella, G.; Janin Rivolin, U. How Sustainable Are Land Use Tools? A Europe-Wide Typological Investigation. Sustainability 2020, 12, 1257. [CrossRef]

55. Dolowitz, D.; Marsh, D. Who Learns What from Whom: A Review of the Policy Transfer Literature. Polit. Stud. 1996, 44, 343-357. [CrossRef]

56. Dolowitz, D.P.; Marsh, D. Learning from Abroad: The Role of Policy Transfer in Contemporary Policy-Making. Governance 2000, 13, 5-23. [CrossRef]

57. Cotella, G.; Janin Rivolin, U.; Santangelo, M. Transferring Good Territorial Governance Across Europe-Opportunities and Barriers. In Territorial Governance across Europe: Pathways, Practices and Prospects; Van Well, L., Schmitt, P., Eds.; Routledge: London, UK, 2016; pp. 238-253. 
58. Macário, R.; Marques, C.F. Transferability of sustainable urban mobility measures. Res. Transp. Econ. 2008, 22, 146-156. [CrossRef]

59. Akaka, M.A.; Vargo, S.L.; Lusch, R.F. The Complexity of Context: A Service Ecosystems Approach for International Marketing. J. Int. Mark. 2013, 21, 1-20. [CrossRef]

60. Everett, P.B.; Pieters, R.G.M.; Titus, P.A. The consumer-environment interaction: An introduction to the special issue. Int. J. Res. Mark. 1994, 11, 97-105. [CrossRef]

61. ESPON. URRUC-Urban-Rural Connectivity in Non-Metropolitan Regions. Annex 2-Conceptualisation and Methodology; European Territorial Observatory Network: Luxembourg, 2019.

62. Brzozowska, A.; Dacko, M.; Gorb, O.O. Importance of logistics in sustainable development of rural areas. Actual. Probl. Econ. 2016, 178, 143-154.

63. Staricco, L.; Vitale Brovarone, E. The spatial dimension of cycle logistics. TeMA J. Land Use Mobil. Environ. 2016, 9, 173-190.

64. Thangavelsamy, K.; Mohapatra, S. Institutional Options for Rural Last Mile Service Delivery Through Digital Governance. In Proceedings of the 19th European Conference on Digital Government, Nikosia, Cyprus, 24-25 October 2019.

65. Zhai, C.X.; Gao, C.; Xiao, Y.; Zhao, Z.; Sun, Z.W. The Construction of the Rural Logistics Network Basing on Crowdsourcing. IOP Conf. Ser. Mater. Sci. Eng. 2018, 392, 062143. [CrossRef]

66. Ambrosino, G.; Nelson, J.D.; Romanazzo, M. Demand Responsive Transport Services: Towards the Flexible Mobility Agency; Enea: Rome, Italy, 2004; ISBN 978-88-8286-043-1.

67. Hunkin, S.; Krell, K. Policy Brief on Demand Responsive Transport; Interreg Europe: Lille, France, 2018.

68. Loveless, S. Access to Jobs: Intersection of Transportation, Social, and Economic Development Policies. In Proceedings of the Refocusing Transportation Planning for the 21st Century Conference, Washington, DC, USA, 7-10 February 2000.

69. Mounce, R.; Wright, S.; Emele, C.D.; Zeng, C.; Nelson, J.D. A tool to aid redesign of flexible transport services to increase efficiency in rural transport service provision. J. Intell. Transp. Syst. 2018, 22, 175-185. [CrossRef]

70. Wright, S.; Emele, C.D.; Fukumoto, M.; Velaga, N.R.; Nelson, J.D. The design, management and operation of flexible transport systems: Comparison of experience between UK, Japan and India. Res. Transp. Econ. 2014, 48, 330-338. [CrossRef]

71. Hines, C. Localization: A Global Manifesto; Routledge: London, UK, 2013; ISBN 978-1-134-19098-0.

72. Shucksmith, M.; Talbot, H.; Talbot, H. Localism and Rural Development. In Reconsidering Localism; Routledge: London, UK, 2015.

73. Abu Mugheisib, E. E-learning in rural areas-German perspective. In Proceedings of the 6th International Multi-Conference on Society, Cybernetics and Informatics (IMSCI), Orlando, FL, USA, 17-20 July 2012.

74. Ashmore, F.H.; Farrington, J.H.; Skerratt, S. Superfast Broadband and Rural Community Resilience: Examining the Rural Need for Speed. Scott. Geogr. J. 2015, 131, 265-278. [CrossRef]

75. Dimmick, S.L.; Mustaleski, C.; Burgiss, S.G.; Welsh, T. A case study of benefits \& potential savings in rural home telemedicine. Home Healthc. Nurse 2000, 18, 124-135. [PubMed]

76. Geurs, K.T.; Gkiotsalitis, K.; Fioreze, T.; Visser, G.; Veenstra, M. The potential of a Mobility-as-a-Service platform in a depopulating area in The Netherlands: An exploration of small and big data. In Advances in Transport Policy and Planning; Elsevier: Amsterdam, The Netherlands, 2018; ISBN 978-0-12-815454-0.

77. Jere, N.R.; Thinyane, M.; Terzoli, A. Development of an ICT Road Map for Eservices in Rural Areas. In Proceedings of the ITU Kaleidoscope 2011: The Fully Networked Human?-Innovations for Future Networks and Services (K-2011), Cape Town, South Africa, 12-14 December 2011.

78. Pimenidis, E.; Sideridis, A.B.; Antonopoulou, E. Mobile devices and services: Bridging the digital divide in rural areas. Int. J. Electron. Secur. Digit. Forensics 2009, 2, 424-434. [CrossRef]

79. Spicer, Z.; Goodman, N.; Olmstead, N. The frontier of digital opportunity: Smart city implementation in small, rural and remote communities in Canada. Urban Stud. 2019. [CrossRef]

80. European Platform on Mobility Management. Mobility Management: The Smart Way to Sustainable Mobility in European Countries, Regions and Cities; EPOMM: Brussels, Belgium, 2013.

81. Jauneikaite, K.; Burinskiene, M. Integration of Mobility Management into Territorial Planning Process in Lithuania; Vilniaus Gedimino Technikos Universitetas: Vilnius, Lithuania, 2008; pp. 959-966. 
82. Vanoutrivespi, T.; van Malderen, L.; Jourquinspi, B.; Thomasspi, I.; Verhetselspi, A.; Witlox, F. Mobility management measures by employers overview and exploratory analysis for Belgium. Eur. J. Transp. Infrastruct. Res. 2010, 10, 121-141.

83. Devins, D.; Darlow, A.; Webber, D. Beyond "access": Internet use and take-up of online services by adults living in disadvantaged areas in England. Local Econ. 2008, 23, 47-57. [CrossRef]

84. Vidal, P.; Mus, M. ICTs, a toll for the setting up of accessible town: The case of disabled people. Flux 2009, 78, 38-48. [CrossRef]

85. Wirtz, B.W.; Kurtz, O.T. Local e-government services: Quality aspects and citizen usage preferences. Electron. Gov. 2018, 14, 160-176. [CrossRef]

86. Ellegård, K.; Svedin, U. Torsten Hägerstrand's time-geography as the cradle of the activity approach in transport geography. J. Transp. Geogr. 2012, 23, 17-25. [CrossRef]

87. Lenntorp, B. Time-geography-At the end of its beginning. GeoJournal 1999, 48, 155-158. [CrossRef]

88. Talpur, M.A.H.; Madzlan, N.; Irfan, A.; Chandio, I.A.; Hussain, S. Time-Space Geography: A Creditable Transport Accessibility Measure for Rural Dwellers. In Applied Mechanics and Materials; Trans Tech Publications Ltd.: Baech, Switzerland, 2014; Volume 567, pp. 763-768.

89. Hansson, J.; Pettersson, F.; Svensson, H.; Wretstrand, A. Preferences in regional public transport: A literature review. Eur. Transp. Res. Rev. 2019, 11, 38. [CrossRef]

90. Te Morsche, W.; La Paix Puello, L.; Geurs, K.T. Potential uptake of adaptive transport services: An exploration of service attributes and attitudes. Transp. Policy 2019, 84, 1-11. [CrossRef]

91. Sitanyiova, D.; Misso, F.E. RUMOBIL-Feasibility of New Public Transport Services in European Rural Areas. IOP Conf. Ser. Mater. Sci. Eng. 2019, 661, 012148. [CrossRef]

92. Vitale Brovarone, E. Pianificazione urbana e comportamenti di viaggio: Più di una relazione. Urban planning and mobility styles: More than a relation. TeMA J. Land Use Mobil. Environ. 2010, 3, 55-62.

93. ESPON. URRUC-Urban-Rural Connectivity in Non-Metropolitan Regions. Annex 6-Case Study Report; Province of Imperia-Valle Arroscia, Italy; European Territorial Observatory Network: Luxembourg, 2019.

94. Jain, S.; Ronald, N.; Thompson, R.; Winter, S. Predicting susceptibility to use demand responsive transport using demographic and trip characteristics of the population. Travel Behav. Soc. 2017, 6, 44-56. [CrossRef]

95. Berg, J.; Ihlström, J. The Importance of Public Transport for Mobility and Everyday Activities among Rural Residents. Soc. Sci. 2019, 8, 58. [CrossRef]

96. Gray, D.; Shaw, J.; Farrington, J. Community transport, social capital and social exclusion in rural areas. Area 2006, 38, 89-98. [CrossRef]

97. Berisha, E.; Cotella, G.; Janin Rivolin, U.; Solly, A. Spatial governance and planning systems and the public control of spatial development: A European typology. Eur. Plan. Stud. 2020,1-20. [CrossRef] 